\title{
NEW INSIGHTS INTO THE HYDROGEOLOGY OF THE OCEANIC CRUST THROUGH LONG-TERM MONITORING
}

\author{
BY MIRIAM KASTNER, KEIR BECKER, EARL E. DAVIS, ANDREW T. FISHER,
} HANS W. JANNASCH, EVAN A. SOLOMON, AND GEOFFREY WHEAT

IMPORTANCE OF CRUSTAL HYDROGEOLOGY AND CORKS

The hydrogeology of the oceanic crust influences numerous global processes and properties, including the thermal evolution of oceanic lithosphere, crustal alteration and the chemistry of crustal fluids, the nature and significance of subseafloor microbial ecosystems, tectonic and volcanic characteristics of active margins, and the creation of hydrate and ore deposits on and below the seafloor. Understanding these processes and properties has been a fundamen- tal goal for scientific ocean drilling for over three decades, but progress has been limited in many cases by a vexing conundrum: drilling into the seafloor often causes open exchange of formation fluids and ocean bottom waters when coring penetrates through sediments and into permeable oceanic basement (e.g., Hyndman et al., 1976; Becker et al., 1983). Such open exchange strongly perturbs in situ conditions and limits validity of borehole measurements to resolve the natural state. These perturbations have greatly limited our ability to quan-

Miriam Kastner (mkastner@ucsd.edu) is Professor of Earth Sciences, Scripps Institution of Oceanography, University of California-San Diego, La Jolla, CA, USA. Keir Becker is Professor, Rosenthiel School of Marine Sciences, University of Miami, Miami, FL, USA. Earl E. Davis is Senior Research Scientist, Geological Survey of Canada, Pacific Geoscience Center, Sidney, British Columbia, Canada. Andrew T. Fisher is Professor, Earth Sciences Department, University of California-Santa Cruz, Santa Cruz, CA, USA. Hans W. Jannasch is Senior Research Specialist, Biogeochemical Instrumentation and Chemical Oceanography, Monterey Bay Aquarium Research Institute, Moss Landing, CA, USA. Evan A. Solomon is Geochemist, Scripps Institution of Oceanography, University of California-San Diego, La Jolla, CA, USA. Geoffrey Wheat is Research Professor, Geological Oceanography, University of Alaska-Fairbanks, Fairbanks, AK, USA.

tify fundamental physical, chemical, and microbiological parameters that control and are controlled by fluid flow within the oceanic crust.

Motivated by this problem, longterm subseafloor observatories were first envisaged in the late 1980s as a means to utilize deep-sea boreholes for understanding in situ hydrogeological state and processes. The original CORK (Circulation Obviation Retrofit Kit) was designed to seal a reentry hole, with basic sensors and samplers suspended within the sealed hole and ports for sample collection at the seafloor (Davis et al., 1991). Long-term monitoring of temperature and pressure signals was originally intended to record the return to in situ conditions and capture signals associated with hydrogeological transients resulting from the subseafloor response to tidal forcing, barometric and oceanographic events, and strain events due to tectonic processes (e.g., Davis and Becker, 2004). Among the original primary goals of early CORK observa- 


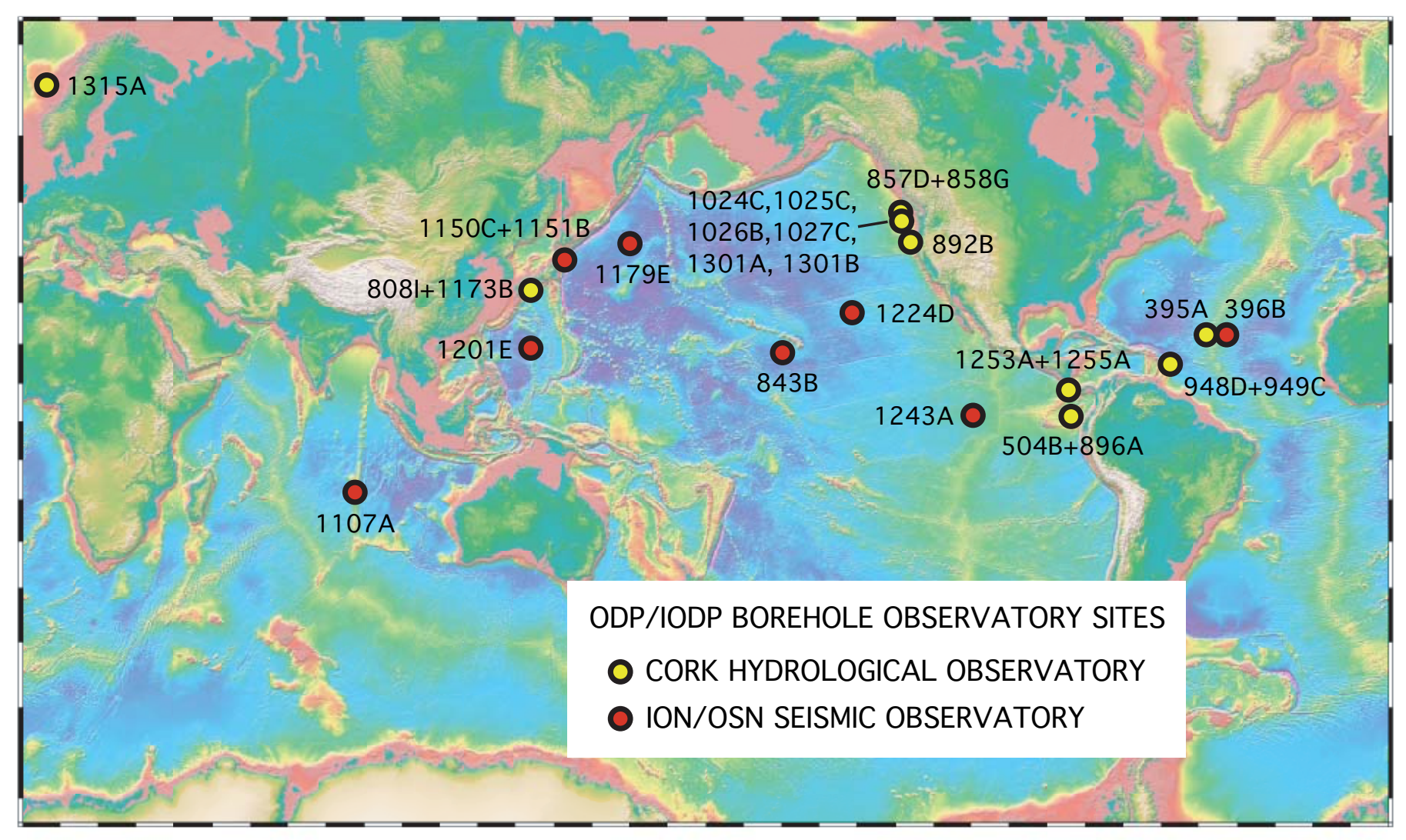

Figure 1. Map showing two main kinds of ODP/IODP long-term borehole observatory sites. The yellow-filled circles mark CORK hydrological observatories, and the red-filled circles mark ION/OSN seismic observatories.

tory efforts were to determine the natural thermal state and driving forces for hydrothermal circulation within the oceanic crust, and to obtain formation fluid samples that were unperturbed. To reach these goals, CORKs were deployed in the sediment-filled Middle Valley rift of the northern Juan de Fuca Ridge (Ocean Drilling Program [ODP] Holes 857D and 858G), on the eastern flank of the Juan de Fuca Ridge (1024C, 1025C, 1026B, 1027C, 1301A, and 1301B), just outboard of the Middle America trench off Costa Rica (1253A), and outboard of the Nankai Trough off Japan (1173B) (Figure 1). In addition, three pre-exist- ing, cased boreholes in ridge-flank settings were converted for instrumentation: North Pond on the western flank of the Mid-Atlantic Ridge (395A), and on the southern flank of the Costa Rica Rift (504B and 896A). Many of these CORKs have a single sealed interval (Figure 2a), but with time and experience, systems with multiple sealed intervals were developed (Figure 2b). Expanding upon these scientific interests, CORKs have been deployed to elucidate subductionrelated process in accretionary systems (Barbados [948D and 949C], Nankai [801I and 1173B], Cascadia [889C], and Costa Rica [1255A]) and non-accretion- ary systems (Mariana [1200C]), and to understand hydrate systematics (Hydrate Ridge [892B]).

The foundation for these CORKs is a cased borehole that taps selected hydrogeologic horizons. In some cases, the horizons are permeable and overpressured, resulting in artificial springs. Such holes have been drilled into sedimented midocean ridges (ODP Legs 139 and 169), hydrothermal systems on ridge flanks (ODP Legs 148 and 168), and in Mariana Forearc mud volcanoes (ODP Leg 195), providing supplies of fluids that can be sampled and manipulated at the seafloor. However, one still needs to be 

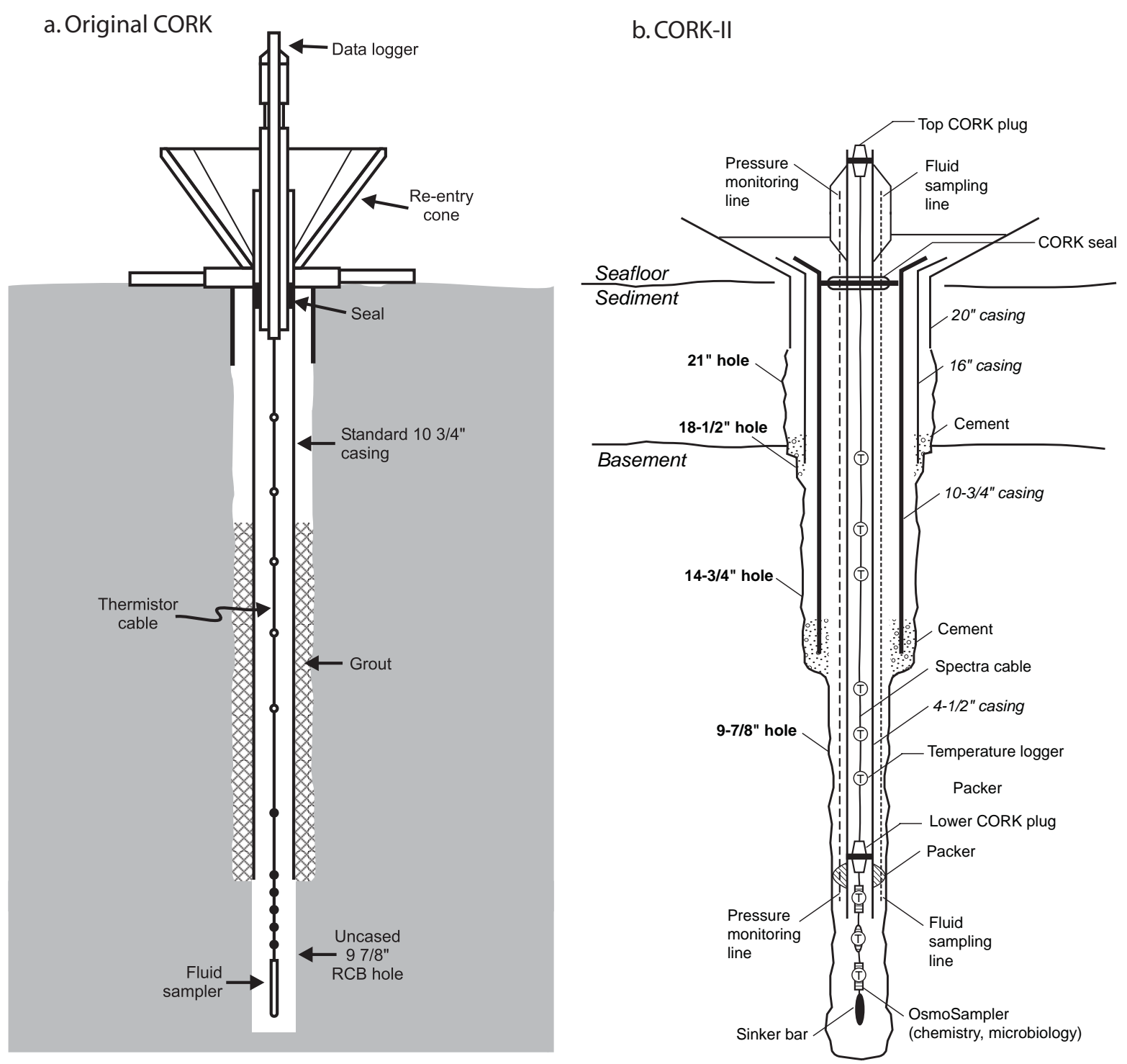

Figure 2. Schematic illustrations of (a) the original CORK design for sampling and monitoring single open-hole intervals and (b) of a "CORK-II," capable of multi-interval sampling and monitoring and utilized during ODP Leg 205 in the Costa Rica subduction zone and IODP Expedition 301 on the eastern flank of the Juan de Fuca Ridge.

concerned with possible artifacts resulting from contamination from basal sediments and borehole itself (e.g., Wheat et al., 2004). These artifacts may influence geochemical and microbial studies using these venting fluids (Cowen et al., 2003). Recently, microbiologists have become interested in CORKed boreholes because traditional methods and low concentrations of organisms inhibit advances in this field.

\section{CORK DESIGN SUMMARY}

From 1991 through 2003, 22 ODP reentry holes were instrumented with two main types of long-term observatories.
Four holes were broadband seismic stations in the western Pacific (two with in situ strainmeters) for teleseismic and whole-Earth tomographic studies in cooperation with the International Ocean Network (ION) (see Sacks, Suyehiro, Acton et al., 2000; Suyehiro et al., this issue) (Figure 1). The remaining 
18 holes were CORK-sealed hydrogeological observatories. A technical review of these CORKs and a complete scientific and technical bibliography through 2004 have been published by Becker and Davis (2005). A new type of CORK was described by Harris et al. (2006); this observatory was deployed to reconstruct bottom-water temperature changes in the Norwegian Sea using temperature data from selected horizons within the borehole.

Even with what appears to be a large number of installations, we are still in an "exploratory" phase and on a relatively steep technological learning curve with each CORK installation. Nevertheless, good data have been collected over the years. Through this technological experience and the desire to broaden the scientific scope and capabilities of these systems, CORKs have evolved, resulting in four general CORK designs described below in order of development (for more detail, see Becker and Davis [2005]).

1. The original CORK has a single seal at the reentry cone from which a data logger and pressure/temperature sensors are suspended in the sealed hole (Figure 2a). Hydraulic access to the sealed hole is provided via a valve at the seafloor. Fourteen of these were installed during ODP in sedimented young oceanic crust or in subduction settings.

2. The "Advanced CORK," or ACORK, incorporates multiple packers on the exterior of the main casing string to seal more than one hydrogeologic zone in a single hole. Umbilicals attached to the outside of the casing penetrate the packers, bringing subseafloor pressure and fluid signals from subseafloor screens attached to the outside of the casing to the wellhead. A separate sensor string can be deployed down the central bore. Two were installed in 2001 in the Nankai Trough accretionary prism.

3. A "wireline CORK" is deployable from a conventional oceanographic ship in a pre-existing reentry hole. A bundled strength/hydraulic/thermistor string includes packers, and hydraulic lines bring formation pressure signals to gauges and valves at the wellhead. Two of these were installed in 2001 in sedimented young ridge flank crust south of the Costa Rica Rift.

4. The "CORK-II" has a modified "instrument hanger" that is suspended in the hole and sealed at the reentry cone (Figure 2b). Hung from the reentry cone at the seafloor is a 4.5 -inch-diameter casing with external packers that are capable of sealing multiple intervals. An umbilical on the outside of the casing brings pressure signals and formation fluids to the wellhead. A separate sensor string can be deployed down the central bore. Two of these systems were installed on the Costa Rica subduction margin (Jannasch et al., 2003). The CORK-II design was then modified before installation during the first IODP expedition in sedimented young ridge flank crust east of the Juan de Fuca Ridge (Fisher et al., 2005).

\section{SENSORS AND SAMPLERS}

Sensors and samplers deployed with the initial CORK installations included devices for pressure and temperature measurements (Davis et al., 1991). Absolute pressure was measured using a single Paroscientific Digiquartz gauge open to the formation. Temperature was measured at 10 discrete locations using thermistors bundled within a cable attached to a data recorder accessible at the seafloor. Paroscientific gauges continue to be used with major upgrades to the dataloggers, providing higher-frequency data collection. In contrast, thermistor cables have been used less in recent installations because of failures at higher temperatures $\left(>50^{\circ} \mathrm{C}\right)$ and advances in autonomous temperature loggers.

Initial attempts for sampling borehole fluids relied on Teflon tubing that was bundled with the thermistor string within the casing. Even in an overpressured hydrogeologic system, this tubing did not work because it was not rigid enough. This problem stemmed the development of a continuous fluid sampler that could be installed at depth. Early samplers were attached to the thermistor cables, either within the cased borehole or below the casing in open hole. The "OsmoSampler" consists of an osmotic pump, originally described by Theeuwes and Yum (1976), and a sample coil (Figure 3a). Flow within the pump is driven by the osmotic pressure differential across a semipermeable membrane that separates solutions of different salinity, providing a slow uniform pump rate. Given this slow pump rate and smallbore sample tubing (1-mm internal diameter [ID]), dispersion is minimized, maintaining temporal signals even for four-year deployments (Jannasch et al., 1994, 2004).

The use of osmotically driven pumps is the basis for the OsmoFlowmeter, which was first deployed in ODP Hole 1255A (Jannasch et al., 2003). A tracer 
solution is added directly at the center of the flowmeter, and four OsmoSamplers sample in each of four directions. Relative flow direction and rate of formation-water flow are determined from dilution of the tracer (Figure 3b). Similarly, osmotic pumps have been deployed for microbiological studies where a known, constant rate of pumping is desired (Fisher et al., 2005). Such studies are needed because of the potential importance of the subseafloor biosphere and our present inability to amplify DNA or incubate microbial populations from a subseafloor basaltic matrix.

Similar to the design of CORK systems, sensors and sampling tools continue to evolve, providing new data to address hydrogeologic problems. For example, seismic data from boreholes at subduction zones will lead to advances in understanding the hydrogeologic response to tectonic events. To meet this challenge, sensor strings that include seismic- and strain-monitoring capabilities are being designed.

\section{APPLICATION OF CORKS FOR PASSIVE MONITORING}

The primary approach taken thus far for determining subseafloor hydrogeologic conditions and properties with CORK observatories is passive: one or more CORK systems are installed and conditions are monitored to take advantage of natural processes and events and/or to document in situ conditions. For example, determining steady-state conditions has helped to resolve the intensity of convection within hydrothermal res-

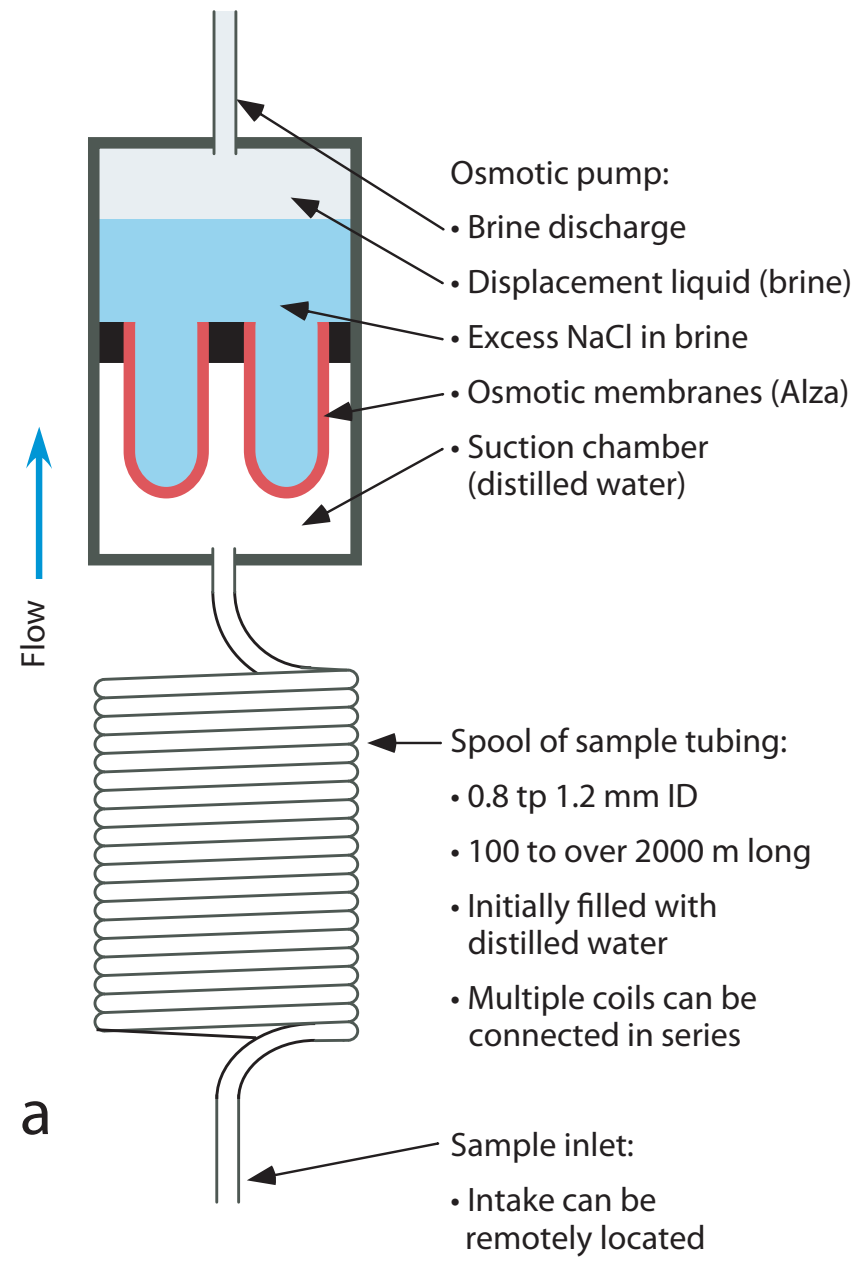

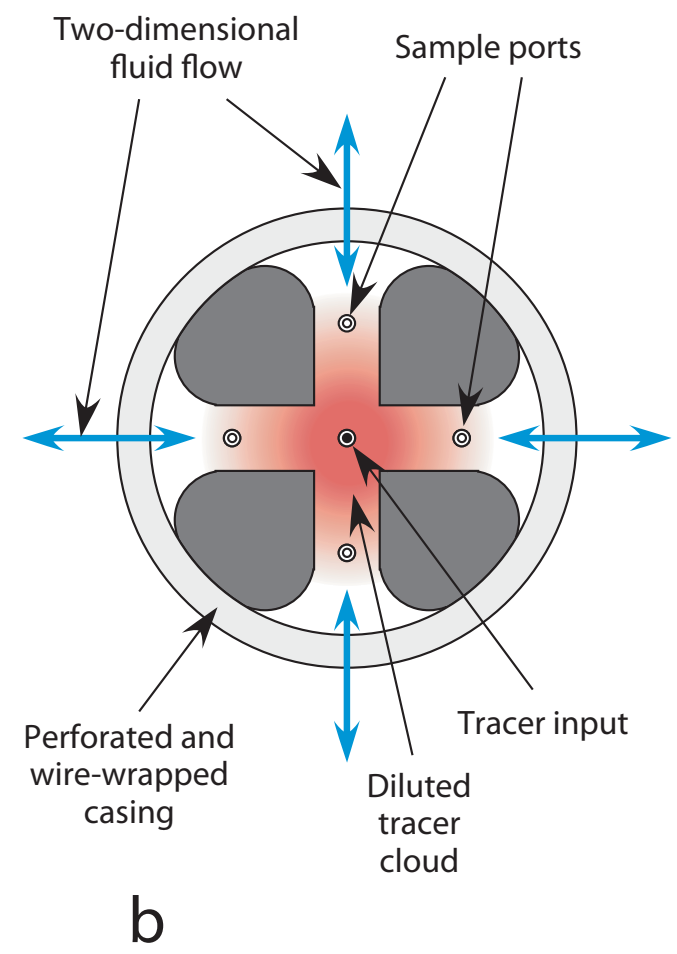

Figure 3. (a) Schematic of an OsmoSampler. The spool of sample tubing is connected to the suction chamber (distilled water) side of the osmotic pump causing flow of the distilled water through the osmotic membrane into the brine discharge chamber; flow direction is designated by the blue arrow. (b) Schematic of an OsmoFlowmeter. Chemical tracers are introduced in the center of the plate, and fluid is continuously drawn with OsmoSamplers at four sample ports. The fluid-flow rate and the relative flow direction are obtained from the tracer dilutions at the four sample ports. 
ervoirs (Davis and Becker, 2001, 2004;

Davis and Fisher, 1994).

One principal result of early CORK observations is that driving forces in most crustal settings are very small. Large pressure differences were recorded across sediment sections with low permeabilities (several hundred $\mathrm{kPa}$ in Middle Valley [a sedimented spreading center on the northern Juan de Fuca Ridge] generated by large thermal buoyancy forces), but pressures within the crust were within a few $\mathrm{kPa}$ of the hydrostatic state defined by the intra-crustal thermal regime. For example, the pressure difference between CORK systems separated by $1.6 \mathrm{~km}$ in Middle Valley is no greater than $\sim 17 \mathrm{kPa}$, once observed absolute pressures are corrected for temperature differences in the sealed boreholes (Stein and Fisher, 2001). This small pressure difference, in combination with the observed hydrothermal vent flux, requires an effective basement permeability on the order of $10^{-12}$ to $10^{-10} \mathrm{~m}^{2}$ within at least one or more thin zones. Similarly, the pressure difference between CORK observatories separated by $2.2 \mathrm{~km}$ on 3.5-3.6 Ma seafloor on the eastern flank of the Juan de Fuca Ridge is no greater than $\sim 2 \mathrm{kPa}$, once again requiring zones with high permeabilities (e.g., Davis and Becker, 2004). Observations of temperature within the upper crust were found to be extremely uniform over lateral distances of several kilometers, suggesting the dominance of advective heat transport over conduction within the upper igneous crust. Numerical models suggest that permeabilities on the order of $10^{-11}$ to $10^{-9} \mathrm{~m}^{2}$ may be required, at least within narrow intervals, to achieve observed thermal homogeneity (e.g., Davis et al., 1997; Spinelli and Fisher, 2004).

A number of other CORK observations came as a "fringe benefit" as drilling perturbations dissipated and unperturbed monitoring epochs grew. Among these was the response to oceanographic loading of the seafloor. By far, the largest signals arose from tides, but seasonal circulation variations, mesoscale eddies, and infra-gravity waves also contributed to producing a loading signal with a broad frequency range. The crustal pressure response (namely the frequency-dependent amplitude and phase of crustal pressure variations relative to seafloor variations) have allowed both elastic (matrix compressibility) and hydrogeologic properties (permeability, storage compressibility) to be determined. Although the number of observed sites is small, there is evidence that the hydraulic and elastic properties are age or alteration-state dependent. For example, inferred matrix compressibilities range from 0.7 to $1.4 \times 10^{-10} \mathrm{~Pa}^{-1}$, with higher values found where crustal temperatures are low and alteration is modest (Becker and Davis, 2004; Davis and Becker, 2004; Davis and Villinger, 2006).

Another application of CORK hydrogeologic monitoring has been the use of pressure as a quantitative proxy for crustal strain. A variety of examples shown in Figure 4 include pressure response to seismic waves and to static strain associated with coseismic strain. Figure $4 \mathrm{~b}$ shows the response at ODP Site 857 to near-field strain associated with a seismogenic seafloor-spreading episode in the Middle Valley rift in 2001. Pressure fell in discrete steps at the times of the largest earthquakes of the associated swarm, then continued to decline for two weeks after the seismic activity was over, either as a consequence of continuing strain or, more likely, when lower pressures generated in the region of greatest dilatation in the hypocentral region diffused to the CORK observation site. Recovery back to the natural hydrogeologic state was slow as a consequence of the poor hydrogeologic connection between the sediment-buried igneous crust in this rift valley and the seafloor. Figure $4 \mathrm{c}$ shows the far-field response to a seafloor-spreading event along the Endeavour ridge segment in 1999. In this instance, the observatory Site 1027 on the Juan de Fuca Ridge flank was in the compressive quadrant of strain, and pressure rose at the time of the event. Despite the great distance to significant areas of basement outcrop where drainage can take place, recovery took place more quickly than in Middle Valley, suggesting that the sediment-buried crust of the ridge flank is more permeable than that of the pervasively altered Middle Valley. Along with providing independent constraints on hydraulic diffusivity, these examples provide direct information about the magnitude of strain associated with these episodes of spreading. In the latter instance, the estimated strain energy was roughly two orders of magnitude greater than the total seismic energy released in the associated earthquake swarm. These numbers suggest that this seafloor-spreading event was dominated by aseismic deep-seated processes. Figure $4 \mathrm{~d}$ shows the response at this same site to the strike-slip displacement that produced a series of earthquakes along the Nootka fault in 1996. In this instance, the site is in the dilatational quadrant of the strain field, and pressure 


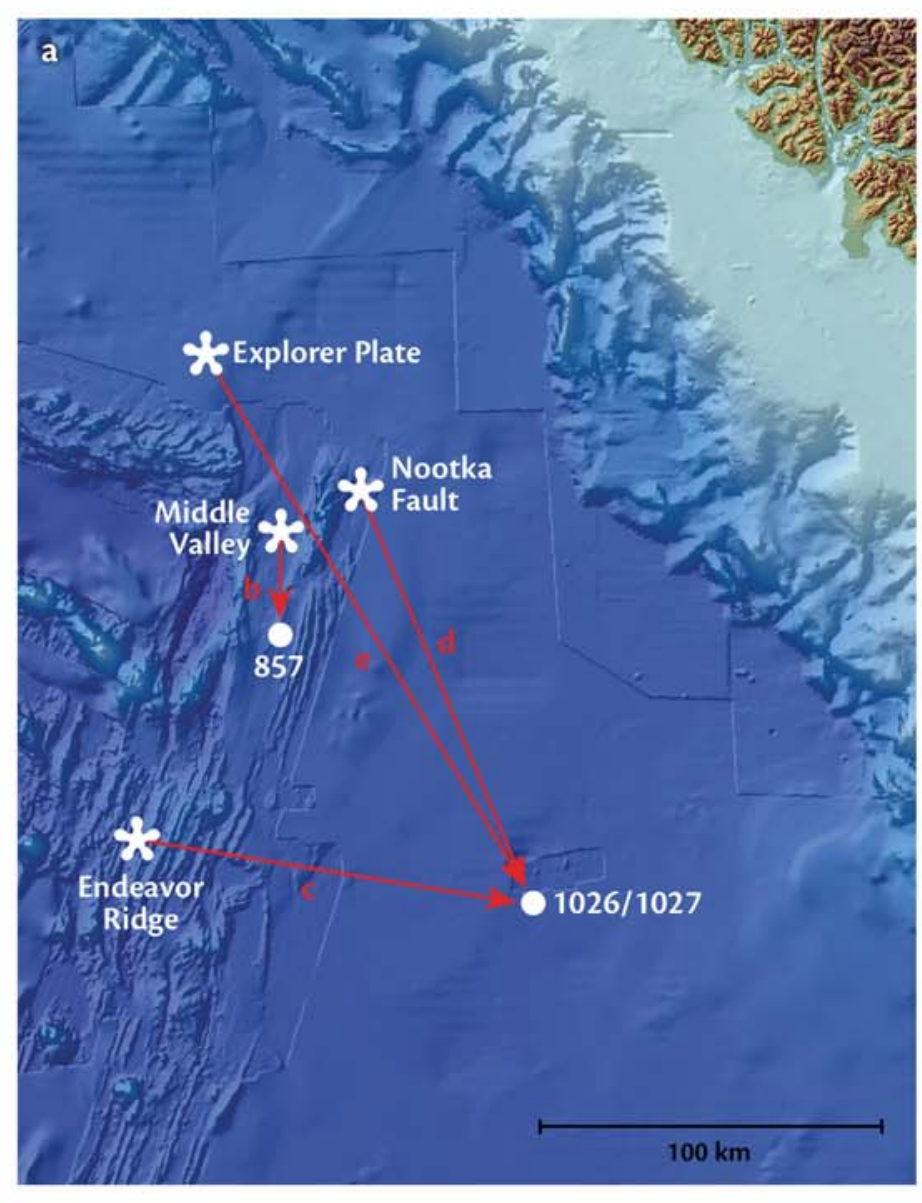

Figure 4. Map (a) shows locations of selected crustal ODP CORK observatory boreholes on the northern Juan de Fuca Ridge and sedimented eastern flank, and a few of the earthquakes that were associated with local or regional crustal strain that has been manifest as pressure signals (b-e) at the observatory sites. In (b), (c), and (d), formation pressures (recorded hourly) are shown relative to the local static background state, and with seafloor loading variations removed. Total pressures recorded with a newgeneration CORK logging system at 15 -sec intervals are shown in (e). In this record, seafloor and borehole response to seismic body waves is superimposed on seafloor and formation tidal pressure variations. A small static strain-related offset in the formation pressure (like those shown in $b-d$ ) is present, but not visible at the scale of this plot.
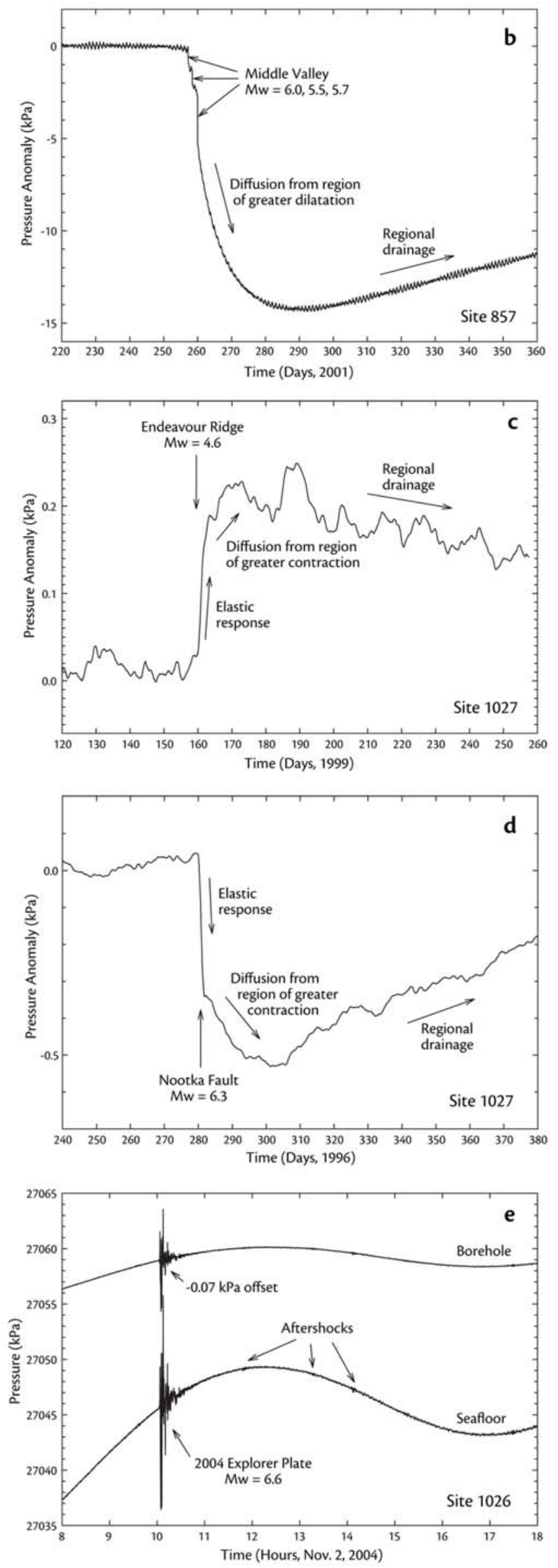
decreased, but otherwise the character of the response, including recovery to the hydrothermally defined pressure state, was similar to that after the 1999 spreading event.

It is important to note that the analyses discussed above are based on idealized aquifer geometry and formation response. In most cases, the oceanic crust is assumed to be fully or transversely isotropic and homogeneous. Most numerical models have been run in two dimensions, and borehole-perturbation response analyses assume axial symmetry. Simplification of geometry and idealization of properties is common practice in hydrogeologic experiments in general, not just those conducted below the seafloor; there is a recognition of the presence of, and a growing interest in, understanding the extent and significance of anisotropy, heterogeneity, network topology, dispersion, and other aspects of hydrogeologic complexity (e.g., Neuman, 2005).

Some constraints for these models come from changes in the fluid composition of borehole fluids as the boreholes recover from drilling. For example, in contrast to temperature and pressure data that recover within weeks on the eastern flank of the Juan de Fuca Ridge, geochemical studies show recovery from drilling operations can take years, depending on the subsurface hydrogeology, but when properly sealed, the holes do recover (Figure 5) (Wheat et al., 2003). The influx of formation fluids into one of these holes (1027C) is about $17.5 \mathrm{~kg}$ day $^{-1}$ once the thermal effects caused by drilling disturbances have dissipated. These data also provide information on the direction and path of flow, showing formation fluids from a sill flowing down in the permeable basement below. In addition, such geochemical studies can determine the degree of fluid contamination and constrain chemical fluxes, including those from diffusive transport from adjacent sediments (Wheat et al., 2004). These two parameters are important to future studies of the subsurface biosphere.

Another chemical record that constrains hydrogeologic processes exists from ODP Hole 1253A just west of the Costa Rica margin. Here, pressures in the upper igneous basement are close to hydrostatic $(-6 \mathrm{kPa})$ and borehole temperatures approach $7.94^{\circ} \mathrm{C}$ after three
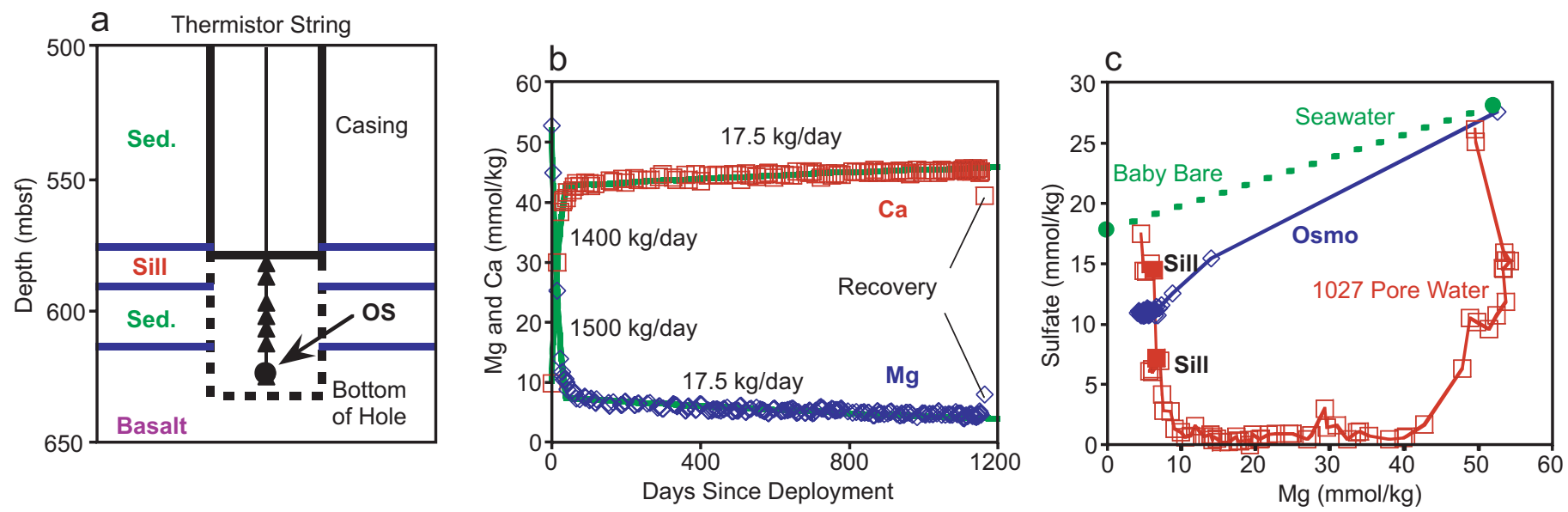

Figure 5. (a) Schematic sketch of thermistor (triangles) and OsmoSamplers (circles) within ODP Hole 1027C, shown in a geologic and operational context. Steel casing penetrated the sediment section and the upper few meters of basalt (sill) and was cemented in place. Additional sediments were encountered, but the open hole terminated within extrusive basement. OsmoSamplers provided a continuous three-year record of fluid composition shown in (b); an initial sharp change in composition is observed during the first 40 days of the deployment, followed by more gradual changes in composition for the remainder of the deployment. Such trends highlight the extent of perturbation caused during drilling, the path and rate of recovery within the formation, and the in situ composition of the formation fluid once the borehole has recovered. These chemical changes are consistent with a flow of seawater through the open borehole at an initial rate of $\sim 1,400 \mathrm{~kg} \mathrm{day}^{-1}$, resulting from drilling disturbances changing the local temperature field. After the return to pre-drilling temperature ( $\sim 40$ days) a more gradual "background" flow of fluid in the borehole ( $\left.17.5 \mathrm{~kg} \mathrm{day}^{-1}\right)$ was observed. Plots of ions versus ions (e.g., sulfate versus $\mathrm{Mg}$ ) shown in (c) for pore fluids (squares), samples from the OsmoSampler (diamonds), seawater, and spring water from the Baby Bare Spring (circles) reveal that the water within the borehole flowed through the sill into the basement, suggesting that basement is under-pressured relative to the sill (modified from Wheat et al., 2004). 
years of monitoring (Davis and Villinger, 2006). These observations are consistent with the upper basement being highly permeable and well connected laterally to points of seawater recharge at distant seamounts where basement outcrops. To whatever depth the upper igneous basement remains permeable, it will serve as an efficient hydrostatic-state drainage pathway for deeper-sourced fluids expelled from the subduction zone. Chemical data are consistent with the rapid influx of formation fluids into the borehole. For example, the chlorinity $(\mathrm{Cl})$ increases from a seawater concentration to a value of $650 \mathrm{mM}$ within 77 days after installation (Figure 6a). Assuming an effective porosity of 5 percent for the upper basement, the average linear velocity $\left(\mathrm{v}_{\mathrm{x}}\right)$ of fluids flowing into the borehole is $45.5 \mathrm{~m} \mathrm{yr}^{-1}$. The sharp drop in chlorinity, as well as other ion ( $\mathrm{Ca}$ and $\mathrm{Mg}$ ) concentrations that tend towards seawater, occurred when the borehole was briefly opened during an Alvin dive in March 2004. The slow recovery implies a change in the influx rate or slow leakage past the seals at the bottom of the CORK-II liner.
The source for this formation fluid is constrained using chemical cross-plots, such as the Ca vs. Mg concentration (Figure 6c). These data are consistent with formation fluids that are a mixture of bottom seawater and altered fluids, possibly a fluid with a similar history as that obtained during the TicoFlux Expedition, about 30-km seaward (Fisher et al., 2003), or a fluid from a deeper source located arcward (Kimura, Silver, Blum et al., 1997).

Additional recent CORK geochemical applications include using samplers de-
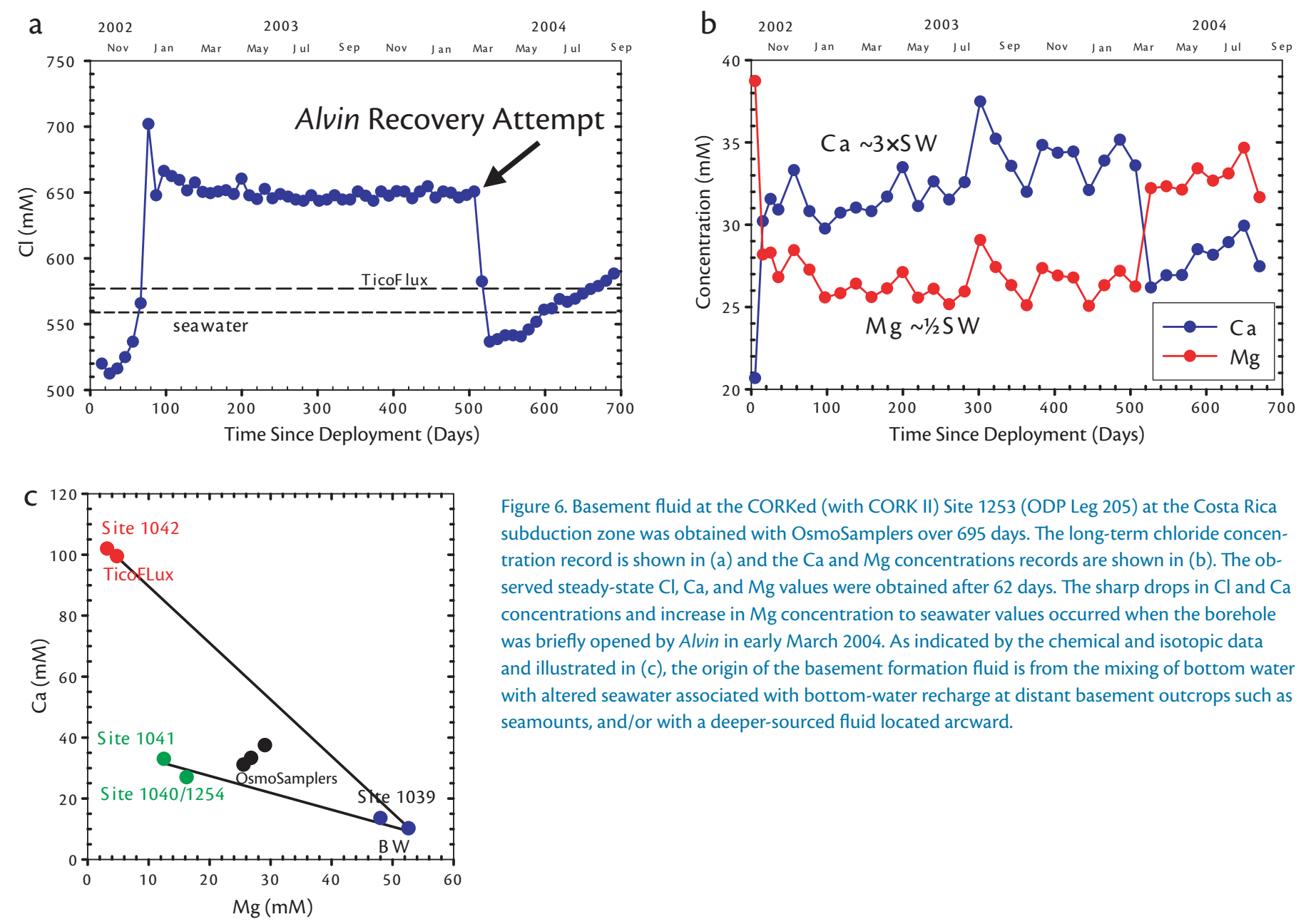

Figure 6. Basement fluid at the CORKed (with CORK II) Site 1253 (ODP Leg 205) at the Costa Rica subduction zone was obtained with OsmoSamplers over 695 days. The long-term chloride concentration record is shown in (a) and the $\mathrm{Ca}$ and $\mathrm{Mg}$ concentrations records are shown in (b). The observed steady-state $\mathrm{Cl}, \mathrm{Ca}$, and $\mathrm{Mg}$ values were obtained after 62 days. The sharp drops in $\mathrm{Cl}$ and $\mathrm{Ca}$ concentrations and increase in $\mathrm{Mg}$ concentration to seawater values occurred when the borehole was briefly opened by Alvin in early March 2004. As indicated by the chemical and isotopic data and illustrated in (c), the origin of the basement formation fluid is from the mixing of bottom water with altered seawater associated with bottom-water recharge at distant basement outcrops such as seamounts, and/or with a deeper-sourced fluid located arcward. 
signed to monitor hydrogeologic tracer tests, measuring relative in situ flow rates and direction, conducting microbial incubation and alteration experiments, and elucidating the interplay between tectonic and hydrogeologic processes (Jannasch et al., 2003; Fisher et al., 2005). For example, the first tectonic-hydrogeologic interaction observed with borehole fluid chemistry was captured in Hole 1255A on the Costa Rica margin. The mechanics of this interaction are unknown, but are the focus of ongoing research.

\section{Active Experiments}

IODP Expedition 301 was carried out on 3.5 Ma seafloor on the eastern flank of the Juan de Fuca Ridge, (Davis et al., 1997; Fisher et al., 2005) near CORKed observatories at Sites 1026 and 1027
(Figure 7). These observatories penetrated $\sim 265 \mathrm{~m}$ and $\sim 600 \mathrm{~m}$, respectively, into sediment and the uppermost 40-50 m of basement, with the intent of documenting variations in hydrogeologic conditions within uppermost basement. Two new observatories were installed at Site 1301, providing the capability to monitor multiple crustal levels within basement and providing the first

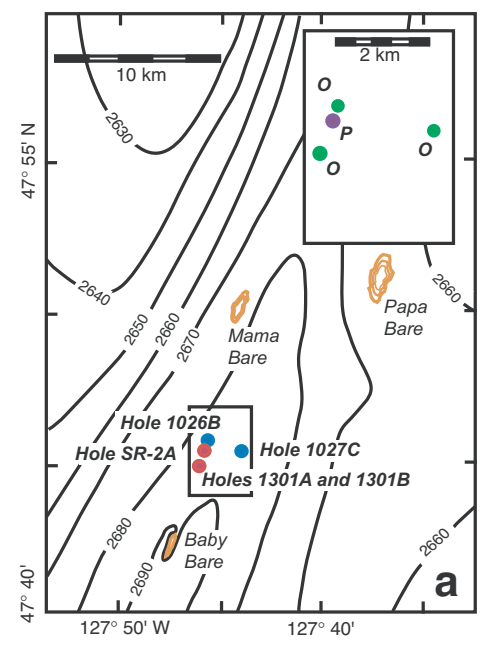

Figure 7. Plans for controlled cross-hole testing on the eastern flank of the Juan de Fuca Ridge. (a) Seafloor bathymetric contour map of area around IODP Expedition 301 sites and the eastern end of the ODP Leg 168 transient, showing spatial relations among CORK observatories (colored circles) in Holes 1026B, 1027C, 1301A, 1301B, planned Site SR-2 (where operations will occur in summer 2008), and nearby basement outcrops (gold bathymetric contours). Depth contours in meters. (b) Perspective basement map of IODP Expedition 301 drilling area, showing ODP and IODP hole locations (modified from Zühlsdorff et al. [2005]). Sediment has been digitally "removed" to show basement relief below the largely flat seafloor. The map is based on bathymetry and interpretation of numerous seismic lines across the area. Holes 1026B and 1301A/B are $\sim 1 \mathrm{~km}$ apart, and Holes $1026 \mathrm{~B}$ and $1027 \mathrm{C}$ are $2.2 \mathrm{~km}$ apart. Hole SR-2B will be the "perturbation" well for three-dimensional, cross-hole experiments that will last several years. (c) Evidence that the upper oceanic crust is hydrogeologically "connected" from Site 1301 to Site 1027C, 2.4 km away. Rig pumping records from Site 1301 and pressure data were downloaded from the CORK system in Hole 1027C. The pressure record has been corrected for tidal loading. There is a clear correlation between pumping in basement in Holes 1301A and 1301B and the pressure response in Hole 1027C (several particularly abrupt "events" marked with red arrows).

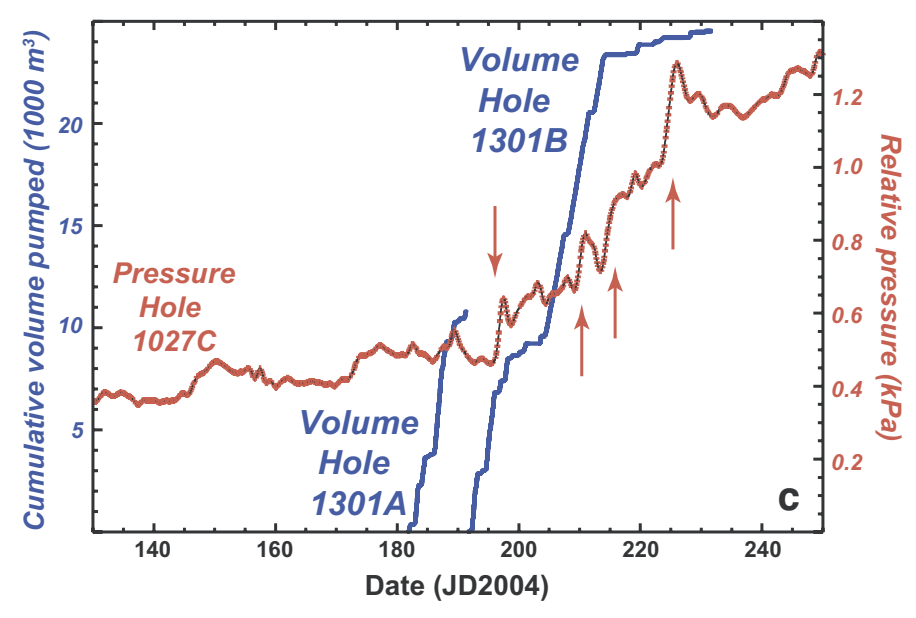


of four new boreholes to conduct active hydrogeologic testing of the upper basaltic crust. Two more observatories will be installed at Site SR-2 during the next drilling expedition, $\sim 200 \mathrm{~m}$ south of Site 1026 and $~ 800$ m north of Site 1301, along the same buried basement ridge (Figure 7b). In addition, the observatory currently emplaced at Site 1027 will be replaced with a next-generation, multilevel CORK. Once these new boreholes are drilled, cased, and instrumented, scientists will initiate a 24-hour pumping test with seawater and tracers, then seal the injection well. Multi-year cross-hole tests also will be initiated by a submersible/remotely operated vehicle one to two years after drilling operations are complete, using the naturally overpressured formation to test properties within an enormous crustal volume.

Data recovered during recent dive operations suggest that experiments of this kind have a good chance of succeeding (Figure 7c). Pumping records from Site 1301 during drilling, casing, and coring operations and pressure data downloaded from the CORK system in Hole 1027C, $2.4 \mathrm{~km}$ to the east, show a positive correlation between shipboard pumping and crustal pressure response (Fisher et al., 2005). Preliminary analysis of these results using a conventional aquifer testing equation suggests bulk basement permeability that is broadly consistent with earlier estimates. Fluid-flow rates and pressures will be carefully monitored during cross-hole experiments completed during and after the next drilling expedition, allowing quantitative interpretation of pressure response in addition to monitoring fluid temperature, chemistry, and possibly microbiology.

\section{CONCLUDING REMARKS}

Recent advances in CORK pressure-sensing and data-recording technologies have provided significantly greater resolution and higher-frequency sampling. These advances have raised the fidelity with which a wide range of both geophysical and oceanographic signals can be observed. The current dynamic range extends over eight orders of magnitude, and signals of this range can be recorded from near-steady state to $0.5 \mathrm{~Hz}$. Observed secular pressure variations in hydrologically well-isolated formations, such as the extensively buried oceanic crust subducting beneath Japan at the Nankai trough, are likely caused by the accumulation of plate strain at this currently locked subduction zone. At the opposite end of the current CORK frequency range, signals from infragravity waves, tsunamis, aseismic deformation, and seismic waves from local and teleseismic sources can be observed. Response to seismic body waves follows approximately the same behavior as the response to oceanographic loading (Figure 4e). Formation pressure is partitioned between the rock matrix and pore fluid in a way that depends on rock, matrix, and fluid compressibilities, and is attenuated relative to the signal observed in the water column. Response to seismic surface waves depends on these same properties, but is a direct consequence of strain; thus, formation pressures exceed those observed at the seafloor. Long-term observations such as those exemplified here are providing new opportunities for the increasingly overlapping disciplines of hydrogeology, geodynamics, seismology, geochemistry, and oceanography. The importance of these observations is highlighted in the final Long-Range Plan for ODP, Understanding Our Dynamic Earth Through Ocean Drilling: Ocean Drilling Program Long Range Plan (1996). The IODP Initial Science Plan also features borehole observatories as both scientific and technological contributions and as a bridge of cooperation to growing national and international initiatives in ocean monitoring (Coffin, McKenzie et al., 2001). The growing community involvement in CORKS includes more than six active IODP proposals that are ready to be scheduled. These proposals generally focus on the coupling of tectonic and hydrogeologic processes in active margins and the role of the hydrothermal process and the subseafloor biosphere in altering upper basaltic basement.

\section{ACKNOWLEDGEMENTS}

We greatly thank T. Pettigrew who from the very beginning provided engineering and technical expertise for the design, construction, installation, and service phases of all CORK projects, R. Macdonald and R. Meldrum of the Geological Society of Canada, and Josh Plant from MBARI. We also thank the crews of the JOIDES Resolution, as well as the pilots, engineers and ship's crews for submersible and remotely operated vehicle operations using the Alvin, Nautile, Jason and Jason II, ROPOS, Kaiko, and Shinkai 6500. Financial support was provided by the National Science Foundation through support to the ODP, and through numerous grants to the scientists involved in these projects, and by the Geological Survey of Canada. 


\section{REFERENCES}

Becker, K., and E.E. Davis. 2004. In situ determinations of the permeability of the igneous oceanic crust. Pp. 189-224 in Hydrogeology of the Oceanic Lithosphere. Cambridge University Press, United Kingdom.

Becker, K., and E.E. Davis. 2005. A review of CORK designs and operations during the Ocean Drilling Program. In: Proceedings of the Integrated Ocean Drilling Program, v. 301, A.T. Fisher, T. Urabe, A. Klaus, and the IODP Expedition 301 Scientists. Integrated Ocean Drilling Program Management International, Inc., Washington, D.C., doi:10.2204/iodp.proc.301.104.

Becker, K., M.G. Langseth, R.P. Von Herzen, and R.N. Anderson. 1983. Deep crustal geothermal measurements, Hole 504B, Costa Rica Rift. Journal of Geophysical Research 88:3,447-3,457.

Coffin, M.F., J.A. McKenzie, and members of the IODP/IPSC Scientific Planning Working Group. 2001. Earth, Oceans, and Life. Scientific Investigations of the Earth System using Multiple Drilling Platforms and New Technologies. Integrated Ocean Drilling Program Initial Science Plan, 2003-2013. International Working Group Support Office, Washington, D.C., 110 pp. [Online] Available at: http://www.iodp.org/isp [last accessed September 4, 2006].

Cowen, J. P., S.J. Giovannoni, F. Kenig, H.P. Johnson, D. Butterfield, M.S. Rappe, M. Hutnak, and P. Lam. 2003. Fluids from aging oceanic crust that support microbial life. Nature 299:120-123.

Davis, E.E., and K. Becker. 2001. Using ODP boreholes for studying sub-seafloor hydrogeology: Results from the first decade of CORK observations. Geoscience Canada 28:171-178.

Davis, E.E., and K. Becker. 2004. Observations of temperature and pressure: Constraints on ocean crustal hydrologic state, properties, and flow. Pp. 225-271 in Hydrogeology of the Oceanic Lithosphere, E.E. Davis and H. Elderfield, eds. Cambridge University Press, United Kingdom.

Davis, E.E., and A.T. Fisher. 1994. On the nature and consequences of hydrothermal circulation in the Middle Valley sedimented rift: Inferences from geophysical and geochemical observations, Leg 139. Pp. 695-717 in Proceedings of the Integrated Ocean Drilling Program, Scientific Results, E.E. Davis, M.J. Mottl, A.T. Fisher, J.F. Slack, and the ODP Leg 139 Scientists, eds. Ocean Drilling Program, Texas A\&M University, College Station, TX.

Davis, E.E., and H.W. Villinger. 2006. Transient formation fluid pressures and temperatures in the Costa Rica forearc prism and subducting oceanic basement: CORK monitoring at ODP Sites 1253 and 1255. Earth and Planetary Science Letters 245:232-244.

Davis, E.E., K. Becker, B. Carson, T. Pettigrew, and R. Macdonald. 1991. CORK: A hydrologic seal and downhole observatory for deep-ocean boreholes. Pp. 43-53 in Proceedings of the Integrated Ocean
Drilling Program, Initial Reports, vol. 139, E.E. Davis, M.J. Mottl, A.T. Fisher, and the ODP Leg 139 Scientists, eds. Ocean Drilling Program, Texas A\&M University, College Station, TX.

Davis, E.E., K. Wang, J. He, D.S. Chapman, H. Villinger, and A. Rosenberger. 1997. An unequivocal case for high Nusselt-number hydrothermal convection in sediment-buried igneous oceanic crust. Earth and Planetary Science Letters 146:137-150.

Fisher, A.T., C. Stein, R. Harris, K. Wang, E. Silver, M. Pfender, M. Hutnak, A. Chrrkaoui, R. Bodzin, and H. Villinger. 2003. Abrupt thermal transition reveals hydrothermal boundary and role of seamounts with the Cocos plate. Geophysical Research Letters 30, doi:10.1029/2002GL016766.

Fisher, A.T., C.G. Wheat, K. Becker, E.E. Davis, H. Jannasch, D. Schroeder, R. Dixon, T.L. Pettigrew, R. Meldrum, R. McDonald, M. Nielsen, M. Fisk, J. Cowen, W. Bach, and K. Edwards. 2005. Scientific and technical design and deployment of longterm, subseafloor observatories for hydrogeologic and related experiments, IODP Expedition 301, eastern flank of Juan de Fuca Ridge. In: Proceedings of the Integrated Ocean Drilling Program, vol. 301, A.T. Fisher, T. Urabe, A. Klaus, and the IODP Expedition 301 Scientists. Integrated Ocean Drilling Program Management International, Inc., Washington, D.C., doi:10.2204/iodp. proc.301.103.

Harris, R.N., and the IODP Expedition 306 Scientists. 2006. Borehole observatory installations on IODP Expedition 306 reconstruct bottom-water temperature changes in the Norwegian Sea. Scientific Drilling 2:28-31.

Hyndman, R.D., R.P. Von Herzen, A.J. Erickson, and J. Jolivet. 1976. Heat flow measurements in deep crustal holes on the Mid-Atlantic Ridge. Journal of Geophysical Research 81:4,053-4,060.

Jannasch, H.W., K.S. Johnson, and C.M. Sakamoto. 1994. Submersible, osmotically pumped analyzers for continuous determination of nitrate in situ. Analytical Chemistry 66:3,352-3,361.

Jannasch, H.W., E.E. Davis, M. Kastner, J.D. Morris, T.L. Pettigrew, J.N. Plant, E.A. Solomon, H.W. Villinger, and G.C. Wheat. 2003. CORK-II: Longterm monitoring of fluid chemistry, fluxes, and hydrology in instrumented boreholes at the Costa Rica subduction zone. Pp. 1-36 in Proceedings of the Ocean Drilling Program, Initial Reports, vol. 205, J.D. Morris and the ODP Leg 205 Scientists, eds. Ocean Drilling Program, Texas A\&M University, College Station, TX, CD-ROM.

Jannasch, H.W., C.G. Wheat, J. Plant, M. Kastner, and D. Stakes. 2004. Continuous chemical monitoring with osmotically pumped water samplers: OsmoSampler design and applications. Limnology and Oceanography: Methods 2:102-113.

Kimura, G., E. Silver, P. Blum, and the ODP Leg 170 Scientists. 1997. Proceedings of the Ocean Drilling Program, Initial Reports, vol. 170. Ocean Drilling
Program, Texas A\&M University, College Station, TX, 458 pp.

Neuman, S.P. 2005. Trends, prospects and challenges in quantifying flow and transport through fractured rocks. Journal of Hydrology 13(1):124-127, doi: 10.1007/s10040-004-0397-2.

Sacks, I.S., K. Suyehiro, G.D. Acton, and the ODP Leg 186 Scientists. 2000. Proceedings of the Ocean Drilling Program, Initial Reports, vol. 186. Ocean Drilling Program, Texas A\&M University, College Station, TX. [Online] Available at: http://www. odp.tamu.edu/publications/186_IR/186ir.htm [last accessed September 4, 2006].

Spinelli, G.A., and A.T. Fisher. 2004. Hydrothermal circulation within rough basement on the Juan de Fuca Ridge flank. Geochemistry, Geophysics, and Geosystems 5(2):Q02001, doi:10.1029/ 2003 GC000616.

Stein, J.S., and A.T. Fisher. 2001. Multiple scales of hydrothermal circulation in Middle Valley, northern Juan de Fuca Ridge: Physical constraints and geologic models. Journal of Geophysical Research 106(B5):8,563-8,580.

Theeuwes, F., and S.I. Yum. 1976. Principles of the design and operation of generic osmotic pumps for the delivery of semisolid or liquid drug formulations. Annals of Biomedical Engineering 4:343-353.

Wheat, C.G., H.W. Jannasch, M. Kastner, J.N. Plant, and E.H. DeCarlo. 2003. Seawater Transport and reaction in upper oceanic basaltic basement: Chemical data from continuous monitoring of sealed boreholes in a mid-ocean ridge flank environment. Earth and Planetary Science Letters 216:549-564.

Wheat, C.G., H.W. Jannasch, M. Kastner, J.N. Plant, E.H. DeCarlo, and G. Lebon. 2004. Venting Formation Fluids from Deep Sea Boreholes in a Ridge Flank Setting: ODP Sites 1025 and 1026. Geochemistry, Geophysics, and Geosystems 5(8): Q08007, doi:10.1029/2004GC000710.

Zühlsdorff, L., M. Hutnak, A.T. Fisher, V. Spiess, E.E. Davis, M. Nedimovic, S. Carbotte, H. Villinger, and K. Becker. 2005. Site surveys related to IODP Expedition 301: ImageFlux (SO149) and RetroFlux (TN116) expeditions and earlier studies. In: Proceedings of the Integrated Ocean Drilling Program, v. 301, A.T. Fisher, T. Urabe, A. Klaus, and the IODP Expedition 301 Scientists. Integrated Ocean Drilling Program Management International, Inc., Washington, D.C. 